\title{
Is Microfracture Alone Enough?
}

\author{
Paul-Gabriel Borodi ${ }^{1}$, Octav Marius Russu ${ }^{1,2, *}$, Andrei Marian Feier ${ }^{1,2}$, Vlad Alexandru Georgeanu ${ }^{3}$, \\ Sándor-György Zuh ${ }^{1,2}$ and Tudor Sorin Pop ${ }^{1,2}$
}

1 Faculty of General Medicine, University of Medicine, Pharmacy, Sciences and Technology George Emil Palade, 540139 Tîrgu Mureș, Romania; borodi.paul@yahoo.com (P.-G.B.); andrei.feier@umfst.ro (A.M.F.); sandor.zuh@umfst.ro (S.-G.Z.); tudor.pop@umfst.ro (T.S.P.)

2 Department of Orthopaedics and Traumatology, Clinical County Hospital, 540139 Tîrgu Mureș, Romania

3 Clinic of Orthopaedic and Trauma Surgery, "St. Pantelimon" Hospital, 021659 Bucharest, Romania; vgeorgeanu@hotmail.com

* Correspondence: octav.russu@umfst.ro; Tel.: +40-2-6521-3720

Citation: Borodi, P.-G.; Russu, O.M.; Feier, A.M.; Georgeanu, V.A.; Zuh, S.-G.; Pop, T.S. Is Microfracture Alone Enough? Appl. Sci. 2021, 11, 7309. https://doi.org/10.3390/app11167309

Academic Editors: Paolo Alberton and Emeline Perrier-Groult

Received: 9 June 2021

Accepted: 6 August 2021

Published: 9 August 2021

Publisher's Note: MDPI stays neutral with regard to jurisdictional claims in published maps and institutional affiliations.

Copyright: (c) 2021 by the authors. Licensee MDPI, Basel, Switzerland. This article is an open access article distributed under the terms and conditions of the Creative Commons Attribution (CC BY) license (https:// creativecommons.org/licenses/by/ $4.0 /)$.

\begin{abstract}
The technique of microfracture (MFX) was first performed 40 years ago and served for many years as the main procedure for repairing cartilage defects. There is a need to improve microfractures because the regenerated cartilage differs from the original histological aspect; it is less hyaline and more fibrocartilaginous. In addition, and more importantly, the benefits do not persist and the long-term results are unsatisfactory. Adjunctive treatments include platelet-rich plasma (PRP), cell-free-based scaffolds, adipose-derived mesenchymal stem cells (ADSCs), and bone marrow aspirate concentrate (BMAC). The aim of this review was to provide an overview and a perspective of the available data regarding MFX and the principal adjunctive treatments from recent years and also to challenge the traditional MFX procedure. We found that cell-free scaffolds, platelet-rich plasma, and bone marrow aspirate concentrate, although they are relatively novel therapies, showed great potential and maintained their clinical benefits for longer periods of time compared to microfracture alone. As for chitosan-based therapy and adipose-derived mesenchymal stem cells, we were not able to form a definitive conclusion. We believe that the available data show promising results, and future research should be done on each topic discussed. Moreover, investigators involved in bone marrow stimulation techniques should focus on conducting prospective comparative studies, performing second-look arthroscopy, and rely on a single enhancement procedure that can be adequately compared with MFX alone.
\end{abstract}

Keywords: microfracture; hyaluronic; platelet-rich plasma; adipose derived mesenchymal stem cells; chitosan-based scaffold

\section{Introduction}

Osteoarthritis (OA) is the most frequent joint pathology worldwide. Approximately $10 \%$ of men and $18 \%$ of women over 60 years old are affected. It can be associated with intense pain and disability, making it a major socioeconomic issue [1].

Today, management strategies are oriented toward symptom control, so conservative treatment should serve as a first-line therapy. Different guidelines have recommended various non-operative treatments, such as exercise, weight control, acetaminophen, transcutaneous electrical nerve stimulation, oral NSAIDs, intra-articular injections, and other methods. The surgical procedure of replacing the joint is reserved for severely affected joints [2].

As a degenerative pathology, OA leads to irreparable cartilage lesions. Although joint replacement is an effective surgical intervention, in order to prevent the development of osteoarticular disease and avoid this major surgical procedure, other less invasive methods should be attempted, such as microfracture (MFX), alone or in combination with intraarticular injection of adipose-derived stem cells (ADSCs), bone marrow aspirate concentrate (BMAC), platelet-rich plasma (PRP), hyaluronic acid (HA), or cell-free scaffolds [3]. 
Cartilage lesions are a common issue and are present in more than $60 \%$ of knees on arthroscopy. About $5 \%$ are seen in younger patients under 40 years old. The management of cartilage lesions represents one of the most challenging problems for the orthopedic community. None of the existing techniques can fully restore the cartilage to its hyaline aspect [4].

The technique of microfracture was first performed 40 years ago and served for many years as a main procedure for repairing cartilage defects. The goal of this intervention is to provide the patient with both surgical and functional benefits. Throughout the years, the technique has constantly been improved by various researchers. There is a need to perfect MFX because the regenerated cartilage differs from the original histological aspect; it is less hyaline and more fibrocartilaginous. Moreover, the MFX procedure uses an awl to penetrate the bone, which leads to subchondral bone alterations such as cysts and a lower subchondral bone health score. These findings may affect clinical outcomes and may be responsible for the biological and mechanical impairment of the fibrocartilage repair tissue in the medium term and, possibly, the long term. Adjunctive treatments include platelet-rich plasma, hyaluronic acid, adipose-derived mesenchymal stem cells, and chitosan-based bioscaffolds (Table 1) [5,6].

Table 1. The main adjuvant treatments with MFX.

\begin{tabular}{cl}
\hline \multicolumn{1}{c}{ Adjuvant MFX } & \multicolumn{1}{c}{ Brief Definition } \\
\hline Mesenchymal stem cells & $\begin{array}{l}\text { Characterized by the capacity to go through self-renewal and multi-lineage differentiation } \\
\text { and create fully differentiated cells [7] }\end{array}$ \\
\hline Platelet-rich plasma & Autologous concentration of human thrombocytes in a small quantity of plasma [8] \\
\hline Hyaluronic acid & $\begin{array}{l}\text { Natively occurring glycosaminoglycan with elasticity and viscosity properties that acts as a } \\
\text { lubricating and shock absorbing liquid in joints [9] }\end{array}$ \\
\hline Chitosan-based scaffolds & $\begin{array}{l}\text { Chitosan, the main constituent, is obtained from de-acetylation of chitin, the structural } \\
\text { component of crustacean shells; it has reduced toxicity and good biocompatibility, } \\
\text { adhesivity, and biodegradability [10] }\end{array}$ \\
\hline Collagen-based scaffolds & $\begin{array}{l}\text { Collagen, the main constituent, is the most abundant protein in the extracellular matrix of } \\
\text { many hard and soft tissues in the human body; the most important is type I collagen, which } \\
\text { provides structural support to resident cells in both types of tissue [11] }\end{array}$ \\
\hline
\end{tabular}

This aim of this review was to give an overview and a perspective of the available data regarding MFX and the principal adjunctive treatments, by carefully searching the main search engines (PubMed/MEDLINE, Web of Science, Cochrane Library, Middle East, Africa), using the following as keywords: microfracture, platelet-rich plasma, hyaluronic, adipose-derived mesenchymal stem cells, bone marrow aspirate concentrate, chitosanbased bioscaffolds, and collagen-based scaffolds. Besides the systematic reviews and metaanalyses that provide practical results in this research area, we also incorporated the results of the newest studies, published in the last five years, and that have not yet been addressed. The strategy also consisted of cross-checking the reference list for relevant articles.

\section{Microfracture Alone}

The procedure starts with the creation of three portals around the knee; for the inflow cannula, the working instruments, and the arthroscope. First, an elaborate evaluation of the knee is carried out, including the suprapatellar pouch, patellofemoral joint, medial and lateral gutters, notch, and medial and lateral compartments. After visualization of the cartilage defect, the uncovered bone is debrided of any remaining cartilage tags by using a resector, and the intact cartilage around the defect is surgically prepared in order to form a pool where a clot can form. The calcified layer of cartilage that remains is delicately detached with a shaver. Caution must be taken not to harm the subchondral bone. Next, an arthroscopic awl is utilized to create a series of holes (microfractures) in the uncovered subchondral bone. The holes are about 3 to $4 \mathrm{~mm}$ apart and with a depth of $4 \mathrm{~mm}$. This is 
the optimal distance that avoids the possible confluence of one hole into another. Typically, the microfractures are started from the periphery, moving to the center of the cartilage defect. After that, blood and droplets of fat from the holes can be observed [5,12,13].

The penetrated subchondral bone plate leads to the formation of a clot in the defect. This clot comprises pluripotent mesenchymal stem cells derived from the marrow, which will fabricate a fibrocartilage repair with varying quantities of type II collagen [14].

Although this is an inexpensive, easy, and popular technique, various studies have reported a series of limitations. The most important are that the benefits are not persistent, and the long-term results are unsatisfactory. Goyal et al. conducted a systematic review of 15 studies, and the overall results showed that microfracture has good results at short-term follow-up, but beyond 5 years postoperatively, failure can be expected, regardless of the size of the lesion. Oussedik et al. also performed a systematic review of bone marrow stimulation techniques, including MFX. They also found good early results, but noted that due to the abnormal new cartilage, unsatisfactory results can be expected in the long run, especially in larger defects $[15,16]$.

\section{Microfracture Plus Scaffolds and Stem Cells}

Over the last few years, mesenchymal stem cell-based treatments for the regeneration of cartilage defects have received significant recognition for various reasons. The capacity of MSCs to turn into connective tissue, such as hyaline cartilage, and the ease of obtaining them from diverse tissues (bone marrow, adipose tissue, trabecular bone, etc.) make them easy targets regarding the harvesting of cells. Among them, ADSCs are easy to obtain for clinical use, with increased isolation yields, and are not altered by the patient's sex, age group, or physiological status. The available studies performed on animals suggest that intra-articular injection of human ADSCs can facilitate regeneration of articular cartilage $[4,17,18]$.

The process includes isolating ADSCs one day before the MFX. The stromal vascular fraction and MSCs are isolated from adipose fragments obtained from the patient. Cells are cultured in T-25 flasks at a final concentration, in order to assess the quantity of mesenchymal-like progenitors in the stromal vascular fraction [19].

After the arthroscopic bone marrow stimulation procedure of MFX described above, a fibrin scaffold is introduced in two separate syringes. One syringe contains lyophilized human plasma fibrinogen in $1 \mathrm{~mL}$ of aprotinin solution and the other has thrombin in a calcium chloride solution. The glue is intended to immediately form a gel when the two solutions are combined. The cell suspension (stromal vascular fraction containing MSCs) is loaded into the thrombin solution in a 1:1 ratio. Then, the cell-thrombin suspension is added to the fibrinogen solution (1:1) using a syringe support system, and they are implanted together into each source on the cartilage lesion surface. The most suitable option for implantation of this cell-thrombin-fibrinogen suspension is through arthroscopic guidance after the arthroscopic liquid is drawn [17].

The available data are in favor of MFX + ADSC therapy. A systematic review conducted by Arshi et al. in 2017 includes 18 articles that compare various MFX + techniques with MFX alone. Out of the 18, two studies dealt with ADSCs as an injectable augmentation to MFX. The outcomes showed statistically significant improvement on the postoperative International Knee Documentation Committee Subjective Knee Form (IKDC) and Knee injury and Osteoarthritis Outcome Score (KOOS) two years after the procedure. After that, only two important studies have been published on this topic. Qiao et al. divided the subjects into three categories: treatment with arthroscopic MFX and intra-articular injection of normal saline (M group), MFX + HA (MS group), and MFX + HA + ADSCs (MSR group). Patients in the MS and MSR groups showed a meaningful response to therapy, based on clinical evaluation of Western Ontario and McMaster Universities Arthritis Index (WOMAC) and 36-Item Short Form Survey (SF-36) scores. Regarding the quantitative evaluation of defect size and cartilage volume by MRI and arthroscopy, the two groups also showed significant improvements. During the first 9 months after treatment, the 
discrepancies between groups were non-significant. However, after 12 months, clinical improvements were significantly greater in the MSR group than the M and MS groups, on most scales. The M group managed to maintain clinical improvement for 9 months; after that, the benefits of microfracture were progressively lost. This finding is in agreement with published studies that also claim that after 1 year the clinical benefits of MFX alone begin to diminish. In the MS and MSR groups, clinical benefits also appeared to diminish after 1 year, but the patient outcomes were still slightly improved at 24-month follow-up compared to baseline. However, these findings are hardly sufficient to recommend ADSCs as an augmentation to MFX, due to the need for an additional surgery $[3,20]$.

Another noteworthy study, conducted by Hashimoto et al., compared MFX alone $(n=4)$ with MFX + ADSCs $(n=7)$. They found no significant differences in preoperative and postoperative IKDC and KOOS scores between the two groups. Despite that, after 48 weeks, the MFX + group had a higher KOOS quality of life (QOL) score compared with the MFX alone group. Moreover, the T2 value (mapping of magnetic resonance images) showed no significant differences, but the mean magnetic resonance observation of cartilage repair tissue (MOCART) score was significantly higher in the MFX + group [21].

Bone marrow aspirate concentrate is another biologic adjunct. Intra-articular delivery of bone marrow concentrate was shown to improve MFX outcomes in full-thickness cartilage defects in a horse model. BMAC concentrations are higher in the iliac crest compared to tibial or femoral bone marrow blood. This finding has led to the development of BMAC and a protective scaffold that can treat chondral lesions when combined with MFX. This is a single-stage procedure, where a large number of multipotent cells are able to differentiate toward the chondral lineage and improve the defect filling and the rate of hyaline-like repair [22,23].

Murphy et al. divided 101 patients into an MFX group $(n=52)$ and MFX + BMAC group $(n=49)$. They compared complications, revision rates, and visual analogue pain scores. They stated that MFX + BMAC appeared to be a safe and effective treatment option for chondral injuries of the talus, decreasing the revision rates without any complications at the donor site [24].

A retrospective study conducted by Jin et al. evaluated MFX alone (group I, 43 cases) and MFX + BMAC (group II, 48 cases). Of these, 64 patients underwent a second-look arthroscopic assessment. Clinical outcomes were similar between the two groups, but the cartilage repair assessment (CRA) grade was significantly higher with BMAC augmentation after two years. Therefore, MFX + BMAC resulted in better cartilage regeneration, although studies with longer follow-ups might be needed to confirm these findings [25].

\section{Microfracture Plus Platelet-Rich Plasma}

Although microfracture is a safe and encouraging treatment for musculoskeletal diseases, evidence of its success has varied greatly and is very indication-specific. After setting the MFX holes, the arthroscopic liquid is cleared from the joint in order to create a dry environment for the application of the PRP mixture. The cubital veins can be used to collect 30 to $45 \mathrm{~mL}$ of whole blood into a $50 \mathrm{~mL}$ syringe that contains sodium citrate. The blood is anticoagulated and centrifuged at $1500 \mathrm{rpm}$ for $10 \mathrm{~min}$. After a second spin of $3000 \mathrm{rpm}$ for $5 \mathrm{~min}$, about $5 \mathrm{~mL}$ of PRP is obtained for each person. The PRP is infiltrated into the knee treated by MFX. This procedure can be repeated regularly, and patients follow a standard rehabilitation protocol [26-28].

PRP can be used to augment MFX due to the ability of platelets to liberate a series of growth factors that have an important role in building higher-quality cartilage. Arshi et al. included the effects of MFX + PRP in their systematic review. They obtained statistically significant improvements in postoperative IDKC and KOOS scores at 2 years. The newest meta-analysis dealing with the evaluation of PRP as an adjuvant for microfracture is by Boffa et al. (2020). They analyzed seven studies that met the inclusion criteria and suggested that PRP can improve the outcomes of MFX in knees and ankles at short-term 
follow-up. However, these ameliorations did not reach minimal clinically important differences (MCIDs), and thus they were not clinically perceivable by patients $[20,29]$.

Recently, Yang et al. conducted a study on 79 patients, divided into a control group of 39 patients treated with MFX + PRP and an observation group of 40 treated by MFX alone. Parameters such as baseline data, pain level, knee range of motion, knee symptoms, motor function, knee function, and complications were evaluated. Significantly statistical results were obtained for IDKC scores $(p<0.05)$ and for Tenger and Lysholm scores $(p<0.05)$. The rate of complications was also better for the group treated with PRP as an adjuvant $(10 \%$, compared to $28 \%$ in the control group). Follow-up was done at 1,2, and 3 months after surgery [30].

\section{Microfracture Plus Cell-Free Injectable Scaffolds}

There are three basic elements in tissue engineering: cells, biodegradable scaffolds, and growth factors, which together provide a new method for the repair of articular cartilage. Scaffolds can provide a 3D structure for cartilage cells and favor cell adhesion and proliferation. They also mediate the signals and interactions between cells. The available literature offers various cell-free injectable scaffolds for treating cartilage lesions, such as HA-based, collagen-based, and chitosan-based [31].

Hyaluronic acid is a lubricant designed to reduce the pain and inflammation of articular surfaces and completes the endogenous joint fluid. Intra-articular injections are utilized for cartilage lesions and joint degeneration. HA has a high-molecular-weight glycosaminoglycan component, which is the reason for its viscoelastic attributes. Moreover, in order to provide joint lubrication and shock absorption, HA represents the main way for proteoglycans of the extracellular matrix to create a hydrated pathway through which cells can migrate [32,33].

As for the procedure itself, HA can be injected 3 weeks after the surgical procedure. Hyaluronic acid-based scaffolds can also be inserted to fill defects in dry conditions with a small arthrotomy. This procedure can be done alone or in combination with other adjuvant therapies [34].

HA as a scaffolding material depends largely on its bulk surface. The parameters that are used to describe the network structure of hydrogels include the molecular weight of the polymer chains, the corresponding mesh size, and the effective network density. HA-based scaffolds can bind to proteins and cells through cell surface receptors, such as CD44, RHAMM, and ICAM-1. HA scaffolds can bind to chondrocytes via CD44. Multiple biological processes mediated by these scaffolds are important for the wound healing process. This, coupled with the capacity to offer an open, hydrated structure for the passage of nutrients, makes them candidates for tissue regeneration and repair techniques [35,36].

Reports on HA as an adjuvant therapy with MFX are shown in Table 2. This table contains the studies published in the last 5 years, with the methodology and results explained. 
Table 2. HA as an adjuvant therapy for microfracture.

Article/Reference

\section{Number of Patients (N)}

Qiao et al. (2020)* [3]

Sofu et al. (2017) [34]

Yontar et al. (2019) [37]

Gobbi et al. (2016) [38]
Saline injection on $1,8,15$, and 22 days after surgery (M group)/HA injection on 1, 8, 15 , and 22 days after MFX (MR group) / ADSC injection on days 1 and 22 and HA injection on days 8 and 22 (MSR group).

HA-based cell-free scaffold used as adjuvant for MFX (group 1, $n=19$ )/MFX alone as surgical procedure (group $2, n=24$ ).

Retrospective evaluation of 20 patients with MFX and HA and cell-free HA-based scaffold combination. American Orthopedic Foot and Ankle Society (AOFAS) Ankle-Hindfoot Scale score and VAS score used to assess postoperative outcomes. Patient satisfaction also questioned.

25 patients treated with MFX alone and 25 with MFX + HA-based scaffold.

\section{Results}

Patients in MS and MSR groups showed meaningful response to therapy based on clinically evaluation with WOMAC and SF-36 scores. Both groups also showed significant improvement in quantitative evaluation of defect size and cartilage volume with MRI and arthroscopy. During the first 9 months after treatment, discrepancies between groups were non-significant; after 12 months, clinical improvement was significantly greater in the MSR group than the M and MS groups on most scales. M group maintained clinical improvement for 9 months. For MS and MSR patients, clinical benefits were still improved at 24 months follow-up compared with baseline.

At 12 and 24 months group 1 showed better results on VAS and Lysholm scores. On Tenger activity scale, group 1 had better activity level after 24 months post MFX. Group 1 returned to non-impact sports at a mean of 7.8 months and group 2 at 9.2 months. MOCART evaluated at 24 months showed full repair in $36.8 \%(n=7)$ of cases in group 1 and $16.6 \%(n=4)$ in group 2 .

Average follow-up period was 20.3 months. AOFAS score increased significantly $(p<0.05)$ postoperatively, from $57.45 \pm 9.37$ to $92.45 \pm 8.4$. VAS score also improved, from $7.05 \pm 2.45$ to $1.65 \pm 2.20$, post MFX $(p<0.05)$. Patient satisfaction: $85 \%$ very satisfied, $5 \%$ satisfied, and $10 \%$ not satisfied. Satisfaction rate: $90 \%$.

Both groups had significant outcome scores at 2 years after treatment. In MFX alone group, $64 \%$ of subjects were considered normal or nearly normal according to IKDC score at 2 years, whereas in MFX + group, all subjects had these results.

MFX + group maintained improvements at 5 years according to Lysholm, Tenger and IKDC objective and subjective scores. Tenger, IKDC objective, and KOOS evaluations showed higher scores in MFX+ group compared with MFX alone at 5 years and Lysholm, and IKDC subjective scores were similar 5 years after the procedure. 
Chitosan is a semi-crystalline polymer, and the amount of crystallinity represents the de-acetylation ability. Due to its stable crystalline composition, chitosan is usually insoluble in aqueous solutions over $\mathrm{pH}$ 7. The polymer has been broadly researched for industrial use, based on film and fiber formation. Given the significance of glycosaminoglycans and their analogs in inducing chondrogenesis, their use as constituents of cartilage tissue scaffolds seems to be a rational approach for improving this process. Chitosan is a partially deacetylated derivate of chitin, extracted from the exoskeletons of arthropods. Chitosan has a linear polysaccharide structure, consisting of beta (1-4) linked D-glucosamine residues, with a varying number of randomly located $\mathrm{N}$-acetyl-glucosamine groups (Figure 1). Chitosan's standard molecular weight can vary from 50 to $1000 \mathrm{kDa}$, depending on the origin and the preparation procedure. Commercially available preparations have levels of de-acetylation that range from 50 to $90 \%$ [39].

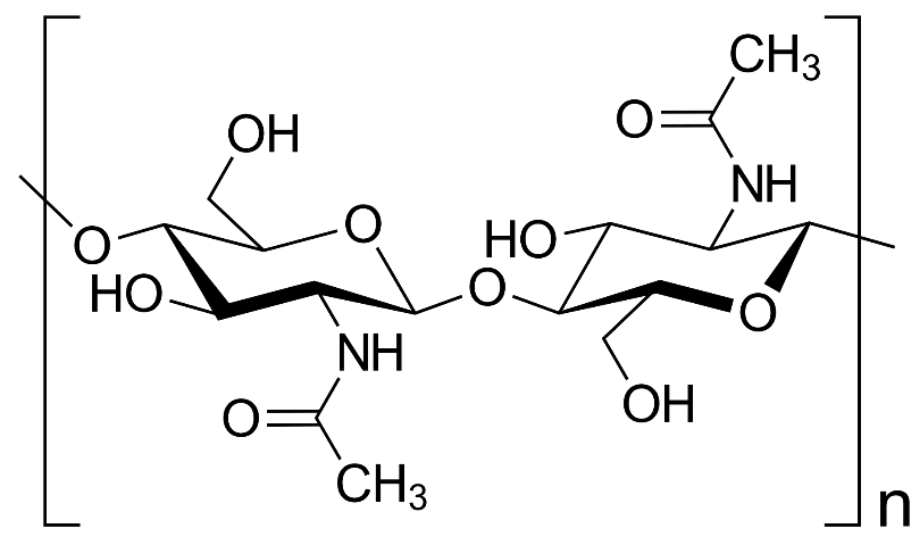

Figure 1. Chemical structure of chitin (Daschnaz 22 August 2007).

Tey et al. described the procedure of applying CBS in hip chondral lesions after MFX. The CBS mixture is prepared according to the manufacturer's instructions. The mixture volume administered per subject varies according to the size of the lesion. Traction should be applied in order to access the central compartment of the femoroacetabular joint. The fluid irrigation is stopped and the articular fluid is aspired. After that, complete drying of the chondral lesion is performed with small swabs, and CBS is inserted with bent 18-gauge needles until the defect is coated. Traction is released after $15 \mathrm{~min}[40,41]$.

Branco da Chuna et al. published the most recent systematic review dealing with various treatments for enhancing MFX, including CBS, in 2020. Out of 10 studies, two included BST-CarGel ${ }^{\circledR}$ (Smith \& Nephew, Andover, MA, USA) as an adjunct to microfracture. The imaging outcomes revealed that one-quarter of patients presented complete full-defect filling, integration of border area, and an intact repaired surface. No adhesions were reported, and significantly better defect filling and lower $\mathrm{T} 2$ relaxation times than MFX were obtained. They also noticed that CBS treatment was associated with knee pain in $11 \%$ of subjects. Overall, MFX + techniques improved patient-reported outcomes over MCID, but offered inconsistent imaging results [42].

Other individual results of CBS as an adjunct to microfracture are explained in Table 3.

Research has revealed that scaffolds made from dehydrated cartilage can stimulate adult stem cells to differentiate down a chondrogenic pathway, producing cells that show morphologic, molecular, and biochemical characteristics that resemble those of articular cartilage cells. The scaffolding allows for hyaline-like cartilage to regenerate within the defect, which enables better structural support for the defect and improved longevity of the repair [43]. 
Table 3. CBS as an adjuvant therapy for microfracture.

\begin{tabular}{|c|c|c|c|}
\hline Article/Reference & $\begin{array}{l}\text { Number of } \\
\text { Patients (N) }\end{array}$ & Method & Results \\
\hline Camurcu et al. (2020) [44] & 63 & $\begin{array}{l}\text { Prospective: Group } 1 \text { received } \\
\text { MF plus chitosan }(n=32) \text { and } \\
\text { group } 2 \text { MFX alone }(n=31) . \\
\text { Mean follow-up was } \\
32 \pm 13 \text { months } \\
(12-61 \text { months). }\end{array}$ & $\begin{array}{l}\text { Significant improvements were observed } \\
\text { postoperatively in both groups on VAS and } \\
\text { AOFAS scores. No statistically significant } \\
\text { difference was noted between groups in terms } \\
\text { of clinical scores. Group } 1 \text { had significantly } \\
\text { higher VAS function score. MOCART scale } \\
\text { showed complete repair with filling of } \\
\text { chondral lesions was more common in group 1, } \\
\text { but not significant enough ( } p=0.257 \\
\text { and } 0.242) \text {. }\end{array}$ \\
\hline Steinwachs et al. (2019) [45] & 91 & $\begin{array}{l}\text { Retrospective evaluation of } \\
\text { patients with cartilage defects } \\
\text { who had MFX } \\
\text { surgery + CARGEL. }\end{array}$ & $\begin{array}{l}\text { No significant changes in range of motion or } \\
\text { T2 value noted from pretreatment to } \\
\text { post-treatment follow-up. Despite this finding, } \\
\text { significant decreases in pain and swelling and } \\
\text { important increases in MOCART II scores ( } p< \\
0.001 \text { ) were observed. Few post-treatment } \\
\text { adverse effects were found. }\end{array}$ \\
\hline Tahoun et al. (2021) [46] & 21 & $\begin{array}{l}\text { Full-thickness acetabular } \\
\text { chondral lesions were filled } \\
\text { with CBS after MFX. After } \\
2 \text { years, T2 mapping was done } \\
\text { for all patients, localizing } \\
9 \text { regions, including the area } \\
\text { of repair. Regions of interest } \\
\text { (ROIs) were compared with } \\
\text { equivalent posterior cartilage. }\end{array}$ & $\begin{array}{l}\text { Zone } 2 \text { was involved in all cases, and zone } 3 \text { in } \\
13 \text { cases. T2 relaxation values were obtained } \\
\text { from } 189 \text { ROIs for quantitative analysis. Mean } \\
\text { T2 values were } 49.1 \text { in peripheral repair zone, } \\
50.2 \text { in central repair zone, and } 46.2 \text { in posterior } \\
\text { cartilage. Conclusion: MFX + CBS induced } \\
\text { homogeneous tissue repair similar to } \\
\text { native cartilage. }\end{array}$ \\
\hline Tahoun et al. (2018) [47] & 23 & $\begin{array}{l}\text { Patients with non-arthritic } \\
\text { non-dysplastic } \\
\text { femoroacetabular } \\
\text { impingement with an } \\
\text { acetabular chondral defect } \\
\text { were included. Defects of } \\
\text { more than } 2 \mathrm{~cm}^{2} \text {; were filled } \\
\text { with CBS after MFX. Mean } \\
\text { follow-up was } \\
38.4 \pm 7 \text { months. }\end{array}$ & $\begin{array}{l}\text { Alpha angle was corrected from a mean of } 70.5 \\
\text { to } 44.3 \text {. Patient-reported outcomes significantly } \\
\text { improved } 1 \text { year compared to pre MFX state } \\
\text { for NAHS, IHOT33, HOS-ADL, and HOS-SSS. } \\
\text { More than } 91 \% \text { met or surpassed MCID. }\end{array}$ \\
\hline
\end{tabular}

NAHS, Non-Arthritic Hip Score; IHOT33, International Hip Outcome Tool 33; HOS-ADL, Hip Outcome Score of Activities of Daily Living; HOS-SSS, Hip Outcome Score of Sports-Specific Scale.

Brusalis et al. conducted a study where they evaluated the short-term outcomes of microfracture augmented with a micronized allograft cartilage matrix (BioCartilage) and PRP for symptomatic focal femoral condyle or trochlea cartilage defects. MRI investigations were performed 1 year after the intervention. At 2 years, the outcomes were evaluated through patient-reported outcome measures (PROMs) and the rates of returnto-work and return-to-sport. They concluded that focal chondral lesions treated with the adjuvant therapy were associated with significant improvements in PROMs 2 years postoperatively [48].

A multicenter randomized controlled trial performed by Lee et al. compared $46 \mathrm{pa}-$ tients divided into two equal groups, one treated with MFX alone and one with MFX plus atelocollagen augmentation. After 2 years of follow-up, the quality of the regenerated cartilage was superior after the augmentation technique. Although all clinical outcomes evaluated were superior in patients who underwent arthroscopic MFX with atelocollagen augmentation, the differences were not statistically significant [49]. 
In another study conducted by Kim et al., 28 patients were divided into two groups; patients who underwent high tibial osteotomy (HTO) with MFX alone or HTO plus MFX and collagen augmentation. One year after treatment, a second-look arthroscopy was performed in order to obtain a biopsy of the repaired cartilage. The quality of the repair after MFX with collagen augmentation was superior compared with MFX alone. In terms of the clinical scores after one year, no differences were observed [50].

Despite all of the above studies regarding collagen-based scaffolds showing great potential, further research is needed to evaluate longer-term outcomes and durability.

\section{Discussion and Future Directions}

Up-to-date evidence regarding the enhancing agents presented in this review highlights that they can serve as routine adjuncts to MFX in the figure. The goal is to produce a hyaline cartilage, and MFX alone has been shown to be prone to failure in this respect, inducing less adequate fibrocartilaginous tissue. Adjuvant therapies are constantly being developed and advanced in terms of biocompatibility, chemical structure, combination strategies, and methods of administration, in order to provide higher-quality tissue. Although they are relatively new approaches, the literature offers other cartilage tissue regeneration techniques that are worth mentioning [51].

One such therapy, which is gaining popularity, is the intra-articular injection of various types of blood-derived products. Kuten-Pella et al., using a 3D osteoarthritic chondrocyte pellet model, evaluated the regenerative potential of two types of PRP, one prepared with EDTA and citrate and an alternative blood product, hyperacute serum (hypACT). They obtained the best results for hypACT and stated that the possible molecular mechanisms of blood-derived products should be investigated in order to obtain the best results [52].

Moreover, due to the significant progress made in genetic and biochemical research in recent years, the molecular basis of cartilage lesions has become better understood. Our understanding of their complex genetic background has led to the development of new targeted therapies. The technology of delivering therapeutic genes to the site of injury and integrating tissue engineering with viral gene vectors is a novel and emerging approach to cartilage renewal. However, despite the encouraging preclinical results, the concept requires more clinical trials in order to become a therapeutic option for cartilage treatment [53].

Another approach worth mentioning consists of a modified gelatin hydrogel that absorbs proteoglycans secreted by chondrocytes near the cartilage tissue in situ and quickly forms an adequate chondrocyte survival microenvironment. Wang et al. evaluated this therapeutic method, and the in vivo and in vitro results showed that the hydrogels were effective and expressed efficient biocompatibility, while promoting the tissue repair of cartilage defects [54].

\section{Limitations}

Despite their potential benefits in preventing the development of OA in a better manner than MFX alone, "plus" therapies face a series of challenges. One has to do with the quality of up-to-date studies on this topic. Future studies should focus on using an adequate randomization process and persist with the intended interventions, as well as have clear outcome data, measurements, and selection of reported results. This would lead to better meta-analyses of the topic. In addition, sample size, baseline imbalances, the retrospective nature of the studies, short follow-up periods, the lack of second-look arthroscopies and histological analysis of new tissue, and the lack of a control group are other common limitations stated in the available studies [20,26].

Most researchers have recognized the benign nature of the postoperative adverse effects and consider adjuvant therapies to be safe, even though some studies could be at risk of bias, because retrospectively evaluating the complications could lead to underestimating the effects [55]. 
Our literature review concerning chitosan-based therapies offered the least promising results. The available systematic review and prospective study gave unconvincing results as to whether this adjuvant is better than MFX alone, due to the lack of a control group. However, individual studies have reported encouraging results, and this should be considered in the future regarding this treatment [41,42].

Despite the promising results shown by ADSCs, as described in the systematic review conducted by Arshi et al. and two individual studies, this is hardly enough to recommend this augmentation technique, due to the need for additional surgery in the process of obtaining these cells $[3,20,21]$.

We believe that the available data show promising results, and future research should be done on each topic discussed. Moreover, investigators involved in bone marrow stimulation techniques should focus on conducting prospective comparative studies, using second look-arthroscopy, and rely on a single enhancement procedure that can be adequately compared with MFX alone.

\section{Conclusions}

The goal of this review was to challenge the traditional MFX procedure by offering up-to-date, comprehensible data regarding novel adjuvant strategies for microfracture. Cell-free-based scaffolds, platelet-rich plasma, adipose-derived mesenchymal stem cells, and bone marrow aspirate concentrate, although being relative novel therapies, showed great potential and maintained clinical benefits for longer periods of time compared to microfracture alone. As for chitosan-based therapy, we were not able to form a definitive conclusion. However, future higher-quality research should be performed on all of these regimens in order for them to be considered standard procedures.

Author Contributions: All authors contributed equally to the manuscript. Data curation, P.-G.B., A.M.F. and V.A.G.; Methodology, P.-G.B., O.M.R. and A.M.F.; Validation, O.M.R., A.M.F., S.-G.Z., V.A.G. and T.S.P.; Writing—review \& editing, P.-G.B., O.M.R., A.M.F., V.A.G., S.-G.Z. and T.S.P.; Writing—original draft, P.-G.B.; Funding acquisition, O.M.R. and T.S.P.; Project administration, O.M.R. and T.S.P.; Resources, V.A.G. and S.-G.Z. All authors have read and agreed to the published version of the manuscript.

Funding: This research received no external funding.

Institutional Review Board Statement: Not applicable.

Informed Consent Statement: Not applicable.

Conflicts of Interest: The authors declare no conflict of interest.

\section{References}

1. Glyn-Jones, S.; Palmer, A.J.R.; Agricola, R.; Price, A.; Vincent, T.L.; Weinans, H.; Carr, A.J. Osteoarthritis. Lancet 2015, $386,376-387$. [CrossRef]

2. Mora, J.C.; Przkora, R.; Cruz-Almeida, Y. Knee osteoarthritis: Pathophysiology and current treatment modalities. J. Pain Res. 2018, 11, 2189-2196. [CrossRef] [PubMed]

3. Qiao, Z.; Tang, J.; Yue, B.; Wang, J.; Zhang, J.; Xuan, L.; Dai, C.; Li, S.; Li, M.; Xu, C.; et al. Human adipose-derived mesenchymal progenitor cells plus microfracture and hyaluronic acid for cartilage repair: A Phase IIa trial. Regen. Med. 2020, 15, 1193-1214. [CrossRef] [PubMed]

4. Predescu, V.; Cristea, S.; Groseanu, F.; Stoian, V.; Prescura, C. Mosaicplasty: A Good Alternative for Restoring Focal Chondral Defects of the Knee. In Proceedings of the 2010 Advanced Technologies for Enhancing Quality of Life at IEEE, Iași, Romania, 15-19 July 2010; pp. 44-47.

5. Steadman, J.R.; Rodkey, W.G.; Briggs, K.K. Microfracture: Its History and Experience of the Developing Surgeon. Cartilage 2010, 1, 78-86. [CrossRef]

6. Shimozono, Y.; Coale, M.; Yasui, Y.; O’Halloran, A.; Deyer, T.W.; Kennedy, J.G. Subchondral Bone Degradation After Micro-fracture for Osteochondral Lesions of the Talus: An MRI Analysis. Am. J. Sports Med. 2017, 46, 642-648. [CrossRef]

7. Bunnell, B.A.; Flaat, M.; Gagliardi, C.; Patel, B.; Ripoll, C. Adipose-derived stem cells: Isolation, expansion and differentiation. Methods 2008, 45, 115-120. [CrossRef]

8. Marx, E.R. Platelet-rich plasma: Evidence to support its use. J. Oral Maxillofac. Surg. 2004, 62, 489-496. [CrossRef]

9. Goa, K.L.; Benfield, P. Hyaluronic Acid. Drugs 1994, 47, 536-566. [CrossRef] 
10. Steinwachs, M.R.; Waibl, B.; Mumme, M. Arthroscopic Treatment of Cartilage Lesions with Microfracture and BST-CarGel. Arthrosc. Tech. 2014, 3, e399-e402. [CrossRef] [PubMed]

11. Davidenko, N.; Schuster, C.F.; Bax, D.V.; Raynal, N.; Farndale, R.W.; Best, S.M.; Cameron, R.E. Control of crosslinking for tailoring collagen-based scaffods stability and mechanics. Acta Biomater. 2015, 25, 131-142. [CrossRef] [PubMed]

12. Steadman, J.R.; Rodkey, W.G.; Singleton, S.B.; Briggs, K.K. Microfracture technique forfull-thickness chondral defects: Technique and clinical results. Oper. Tech. Orthop. 1997, 7, 300-304. [CrossRef]

13. Halmaciu, I.; Suciu, B.A.; Trambitas, C.; Vunvulea, V.; Ivanescu, A.; Clipa, A.; Adascalitei, P.; Brinzaniuc, K.; Fodor, D. Is it Useful to Use Plastic Models in Teaching Human Anatomy? Mater. Plast. 2018, 3, 414-418. [CrossRef]

14. Mithoefer, K.; Williams, R.J.; Warren, R.J.; Potter, H.G.; Spock, C.K.; Jones, E.C.; Wickiewicz, T.L.; Mark, R.G. The microfracture technique for the treatment of articular cartilage lesions in the knee. A prospective cohort study. J. Bone Joint Surg. Am. 2005, 87, 1911-1920. [CrossRef]

15. Goyal, D.; Keyhani, S.; Lee, E.H.; Hui, J.H.P. Evidence-Based Status of Microfracture Technique: A Systematic Review of Level I and II Studies. Arthrosc. J. Arthrosc. Relat. Surg. 2013, 29, 1579-1588. [CrossRef] [PubMed]

16. Oussedik, S.; Tsitskaris, K.; Parker, D. Treatment of Articular Cartilage Lesions of the Knee by Microfracture or Autologous Chondrocyte Implantation: A Systematic Review. Arthrosc. J. Arthrosc. Relat. Surg. 2015, 31, 732-744. [CrossRef]

17. Koh, Y.-G.; Kwon, O.-R.; Kim, Y.-S.; Choi, Y.-J.; Tak, D.-H. Adipose-Derived Mesenchymal Stem Cells with Microfracture Versus Microfracture Alone: 2-Year Follow-up of a Prospective Randomized Trial. Arthrosc. J. Arthrosc. Relat. Surg. 2016, 32, 97-109. [CrossRef] [PubMed]

18. Xu, X.; Shi, D.; Liu, Y.; Yao, Y.; Dai, J.; Xu, Z.; Chen, D.; Teng, H.; Jiang, O. In vivo repair of full-thickness cartilage defect with human Ipsc-derived mesenchymal progenitor cells in a rabbit model. Exp. Ther. Med. 2017, 14, 239-245. [CrossRef]

19. Lee, K.B.L.; Wang, V.T.Z.; Chan, Y.H.; Hui, J.H.P. A Novel, Minimally-Invazive Technique of Cartilage Repair in the Human Knee Using Arthroscopic Microfracture and Injections of Mesenchymal Stem Cells and Hyaluronic Acid-A Prospective Comparative Study on Safety and Short-Term Efficacy. Ann. Acad. Med. Singap. 2012, 41, 511-517.

20. Arshi, A.; Fabricant, D.; Go, D.E.; Williams, R.J.; McAllister, D.R.; Jones, K.J. Can Biologic Augumentation Improve Clinical Outcomes Following Microfracture for Symptomatic Cartilage Defects of the Knee? A Systematic Review. Cartilage 2018, 9, 146-155. [CrossRef]

21. Hashimoto, Y.; Nishida, Y.; Takahashi, S.; Nakamura, H.; Mera, H.; Kashiwa, K.; Yoshiya, S.; Inagaki, Y.; Uematsu, K.; Tanaka, Y.; et al. Transplantation of autologous bone marrow-derived mesenchymal stem cells under arthroscopic surgery with microfracture versus microfracture alone for articular cartilage lesions in the knee: A multicenter prospective randomized control clinical trial. Regen. Ther. 2019, 11, 106-113. [CrossRef]

22. Fortier, L.A.; Potter, H.G.; Rickey, E.J.; Schnabel, L.V.; Foo, L.F.; Chong, L.R.; Stokol, T.; Cheetham, J.; Nixon, A.J. Concentrated Bone Marrow Aspirate Improves Full-Thickness Cartilage Repair Compared with Microfracture in the Equine Model. J. Bone Jt. Surg. Am. Vol. 2010, 92, 1927-1937. [CrossRef]

23. Gigante, A.; Cecconi, S.; Calcagno, S.; Busilacchi, A.; Enea, D. Arthroscopic Knee Cartilage Repair with Covered Microfracture and Bone Marrow Concentrate. Arthrosc. Tech. 2012, 1, e175-e180. [CrossRef]

24. Murphy, E.P.; McGoldrick, N.P.; Curtin, M.; Kearns, S.R. A prospective evaluation of bone marrow aspirate concentrate and microfracture in the treatment of osteochondral lesions of the talus. Foot Ankle Surg. 2019, 25, 441-448. [CrossRef] [PubMed]

25. Jin, Q.-H.; Chung, Y.-W.; Na, S.-M.; Ahn, H.-W.; Jung, D.-M.; Seon, J.-K. Bone marrow aspirate concentration provided better results in cartilage regeneration to microfracture in knee of osteoarthritic patients. Knee Surg. Sports Traumatol. Arthrosc. 2021, 29, 1090-1097. [CrossRef] [PubMed]

26. Shahin, A.E.; Elseedy, A.E.I.; Ahmed, G.A. Combined Effect of Subchondral Microfracture \& Platelet-rich Plasma in Small Full Thichness Articular Cartilage Lesions of the Knee Joint. Egypt. Orthop. J. 2020, 55, 35-40.

27. Wang, K.C.; Frank, R.M.; Cotter, E.J.; Christian, D.R.; Cole, B.J. Arthroscopic Management of Isolated Tibial Plateau Defect with Microfracture and Micronized Allogeneic Cartilage-Platelet-Rich Plasma Adjunct. Arthrosc. Tech. 2017, 6, e1613-e1618. [CrossRef]

28. Le, A.D.K.; Enweze, L.; De Baun, M.R.; Dragoo, J.L. Platelet-Rich Plasma. Clin. Sports Med. 2019, 38, 17-44. [CrossRef]

29. Boffa, A.; Previtali, D.; Altamura, S.A.; Zaffagnini, S.; Candrian, C.; Filardo, G. Platelet-Rich Plasma Augmentation to Microfracture Provides a Limited Benefit for the Treatment of Cartilage Lesions: A Meta-analysis. Orthop. J. Sports Med. 2020, 21, 2325967120910504. [CrossRef]

30. Yang, Z.; Wu, Y.; Yin, K.; Xiang, J.; Liu, C.; Chen, W.; Dai, Z. The therapeutic value of arthroscopic microfracture technique in combination with platelet-rich plasma injection for knee cartilage injury. Am. J. Transl. Res. 2021, 13, $2694-2701$.

31. Cao, Z.; Dou, C.; Dong, S. Scaffolding Biomaterials for Cartilage Regeneration. J. Nanomater. 2014, 2014, 1-8. [CrossRef]

32. Strauss, E.J.; Barker, J.U.; Kercher, J.S.; Cole, B.J.; Mithoefer, K. Augumentation Strategies following the Microfracture Technique for Repair of Focal Chondral Defects. Cartilage 2010, 1, 145-152. [CrossRef] [PubMed]

33. Görmeli, G.; Karakaplan, M.; Görmeli, C.A.; Sarıkaya, B.; Elmalı, N.; Ersoy, Y. Clinical Effects of Platelet-Rich Plasma and Hyaluronic Acid as an Additional Therapy for Talar Osteochondral Lesions Treated with Microfracture Surgery. Foot Ankle Int. 2015, 36, 891-900. [CrossRef]

34. Sofu, H.; Kockara, N.; Oner, A.; Camurcu, Y.; Issin, A.; Sahin, V. Results of Hyaluronic Acid-Based Cell-Free Scaffold Application in Combination with Microfracture for the Treatment of Osteochondral Lesions of the Knee: 2-Year Comparative Study. Arthrosc. J. Arthrosc. Relat. Surg. 2017, 33, 209-216. [CrossRef] [PubMed] 
35. Collins, M.N.; Birkinshaw, C. Hyaluronic acid based scaffolds for tissue engineering-A review. Carbohydr. Polym. 2013, 92, 1262-1279. [CrossRef]

36. Kim, M.S.; Chun, C.H.; Wang, J.H.; Kim, J.G.; Kang, S.B.; Yoo, J.D.; Chon, J.G.; Kim, M.K.; Moon, C.W.; Chang, C.B.; et al. Microfractures Versus a Porcine-Derived Collagen-Augumented Chondrogenesis Technique for Treating Knee Cartilage Defects: A Multicenter Randomized Controlled Trial. Arthroscopy 2020, 36, 1612-1624. [CrossRef]

37. Yontar, N.S.; Aslan, L.; Can, A.; Ogut, T. One step treatment of talus osteochondral lesions with microfracture and cell free hyaluronic acid based scaffold combination. Acta Orthop. Traumatol. Turc. 2019, 53, 372-375. [CrossRef]

38. Gobbi, A.; Whyte, G.P. One-Stage Cartilage Repair Using a Hyaluronic ACID-Based Scaffold with Activated Bone Mar-rowDerived Mesenchymal Stem Cells Compared with Microfracture: Five-Year Follow-up. Am. J. Sports Med. 2016, 44, $2846-2854$. [CrossRef]

39. Suh, J.-K.F.; Matthew, H.W.T. Application of chitosan-based polysaccharide biomaterials in cartilage tissue engineering: A review. Biomaterials 2000, 21, 2589-2598. [CrossRef]

40. Tey, M.T.; Mas, J.; Pelfort, X.; Monllau, C. Arthroscopic Treatment of Hip Chondral Defects with Bone Marrow Stimulation and BST-CarGel. Arthrosc. Tech. 2015, 4, e29-e33. [CrossRef] [PubMed]

41. Birlutiu, R.M.; Roman, M.D.; Cismasiu, R.S.; Fleaca, S.R.; Popa, C.M.; Mihalache, M.; Birlutiu, V.; Fleaca, S.R. Sonication contribution to identifying prosthetic joint infection with Ralstonia pickettii: A case report and review of the literature. BMC Musculoskelet. Disord. 2017, 18, 311. [CrossRef] [PubMed]

42. Da Cunha, C.B.; Andrade, R.; Veloso, T.R.; Learmonth, D.A.; Espregueira-Mendes, J.; Sousa, R.A. Enhanced microfracture using acellular scaffolds improves results after treatment of symptomatic focal grade III/IV knee cartilage lesions but current clinical evidence does not allow unequivocal recommendation. Knee Surg. Sports Traumatol. Arthrosc. 2020, 28, 3245-3257. [CrossRef]

43. Hihara, A.M.; Mueller, K.W. BioCartilage: A New Biomaterial to Treat Chondral Lesions. Sports Med. Arthrosc. Rev. 2015, 23, 143-148. [CrossRef]

44. Camurcu, Y.; Üçpunar, H.; Yapici, F.; Karakose, R.; Ozcan, S.; Cobden, A.; Duman, S.; Sofu, H. Clinical and Magnetic Resonance Imaging Outcomes of Microfracture Plus Chitosan/Blood Implant vs Microfracture for Osteochondral Lesions of the Talus. Foot Ankle Int. 2020, 41, 1368-1375. [CrossRef]

45. Steinwachs, M.; Cavalcanti, N.; Reddy, S.M.V.; Werner, C.; Tschopp, D.; Choudur, H.N. Arthroscopic and open tratment of cartilage lesions with BST-CARGEL scaffold and microfracture: A cohort study of consecutive patients. Knee 2019, 26, 174-184. [CrossRef]

46. Tahoun, M.F.; Tey, M.; Ormazbal, I.; Elsayed, A.S.; Said, H.G.; Monllau, J.C. Promising radiological outcome after repair of acetabular chondral defects by microfracture augumented with chitosan-based scaffold: Mid-term T2 mapping evaluation. Knee Surg. Sports Traumatol. Arthrosc. 2021, 29, 324-328. [CrossRef]

47. Tahoun, M.F.; Tey, M.; Mas, J.; Eid, T.A.E.; Monllau, J.C. Arthroscopic Repair of Acetabular Cartilage Lesions by Chitosan-Based Scaffold: Clinical Evaluation at Minimum 2 Years Follow-up. Arthroscopy 2018, 34, 2821-2828. [CrossRef] [PubMed]

48. Brusalis, C.M.; Greditzer, H.G.; Fabricant, P.D.; Stannard, J.P.; Cook, J.L. BioCartilage augumentation of marrow stimulation procedures for cartilage defects of the knee: Two-year clinical outcomes. Knee 2020, 27, 1418-1425. [CrossRef]

49. Lee, Y.K.; Young, K.W.; Kim, J.S.; Lee, H.S.; Cho, W.J.; Kim, H.N. Arthroscopic microfracture with atelocollagen augumentation for osteochondral lesion of the talus: A multicenter randomized controlled trial. BMC Musculoskelet Disord 2020, 21, 716. [CrossRef] [PubMed]

50. Kim, M.S.; Koh, I.K.; Choi, Y.J.; Pak, K.H.; In, Y. Collagen Augmentation Improves the Quality of Cartilage Repair after Microfracture in Patients Undergoing High Tibial Osteotomy: A Randomized Controlled Trial. Am. J. Sports Med. 2017, 45, 1845-1855. [CrossRef] [PubMed]

51. Green, C.J.; Beck, A.; Wood, D.; Zheng, M.H. The biology and clinical evidence of microfracture in hip preservation surgery. J. Hip Preserv. Surg. 2016, 3, 108-123. [CrossRef]

52. Kuten-Pella, O.; De Luna, A.; Kramer, K.; Neubauer, M.; Nehrer, S.; Lacza, Z. Regenerative Potential of Blood-Derived Products in 3D Osteoarthritic Chondrocyte Culture System. Curr. Issues Mol. Biol. 2021, 43, 665-675. [CrossRef]

53. Szwedowski, D.; Szczepanek, J.; Paczesny, Ł.; Pękała, P.; Zabrzyński, J.; Kruczyński, J. Genetics in Cartilage Lesions: Basic Science and Therapy Approaches. Int. J. Mol. Sci. 2020, 21, 5430. [CrossRef]

54. Wang, K.Y.; Jin, X.Y.; Ma, Y.H.; Cai, W.J.; Xiao, W.Y.; Li, Z.W.; Qi, X.; Ding, J. Injectable stress relaxation gelatin-based hydrogels with positive surface charge for adsorption of aggrecan and facile cartilage tissue regeneration. J. Nanobiotechnol. 2021, 19, 214. [CrossRef]

55. Rhee, C.; Amar, E.; Glazebrook, M.; Coday, C.; Wong, I.H. Safety Profile and Short-term Outcomes of BST-CarGel as an Adjunct to Microfracture for the Treatment of Chondral Lesions of the Hip. Orthop. J. Sports Med. 2018, 10, 2325967118789871. [CrossRef] 